\title{
The Student Science Writing Competition of the Nova Scotian Institute of Science
}

\author{
HANK BIRD \\ Nova Scotian Institute of Science
}

The Nova Scotian Institute of Science (NSIS) has sponsored the Student Science Writing Competition (SSWC) since 2003. Its objective is to encourage students to practice and improve their science writing skills, and to recognize high levels of writing achievement. The competition is open to any student registered at a university or college in Nova Scotia. Monetary awards are given to undergraduate and postgraduate students as an incentive to participate.

The SSWC has attracted increasing interest in recent years. The number of students expressing intent to enter and the number submitting manuscripts have approximately doubled since 2008-09.

The SSWC is an annual competition. In the Fall semester of each year, notices are sent to all deans and science departments in the province, asking faculty to encourage students to enter. At the same time, the competition is advertised on student-related social media. Students are directed to the NSIS website for further detailed information, and are asked to indicate their interest by the end of December. They are also requested to submit their manuscripts by a specified date in mid-February.

Students are advised that their papers should be directed at a general audience with an interest in science, and not at specialists in their particular field of study. The submissions are expected to conform to scientific research and writing standards. Papers generally fall into two categories - survey papers that describe a current aspect of science, or a description of some of the student's own original research. Students are expected to provide their insights and interpretations about the significance of the chosen topic.

A panel of judges reads and evaluates the submissions. Most judges are selected from the NSIS Council and represent a range of scientific disciplines. After considerable individual assessment and collective discussion, the judges select the undergraduate and 
postgraduate winners, and sometimes submissions that deserve Honorable Mentions. Awards are presented at the beginning of the NSIS monthly public lecture in April. Winners are invited to submit their papers for consideration as a publication in the Institute's journal, Proceedings of the Nova Scotian Institute of Science. 